\title{
Interaction between resting pulmonary ventilation function and cardiac autonomic function assessed by heart rate variability in young adults
}

\author{
Tomoko Kurosawa ${ }^{1}$, Toyoto Iwata ${ }^{1}$, Miwako Dakeishi ${ }^{1}$, Tomoko Ohno ${ }^{1,2}$, Mikako TsukadA ${ }^{2}$ and Katsuyuki \\ MURATA $^{1}$ \\ ${ }^{1}$ Department of Environmental Health Sciences, Akita University School of Medicine and ${ }^{2}$ Seirei Women's Junior College, Akita, Japan \\ (Received 4 May 2007; and accepted 8 June 2007)
}

\begin{abstract}
An association between ambient air pollution and reduced cardiac autonomic function assessed by heart rate variability (HRV) mainly in elderly persons has been suggested by a number of epidemiological studies, but the link between the HRV and pulmonary function in humans remains unknown although such air pollution should primarily affect pulmonary function. To clarify this link, pulmonary ventilation parameters such as oxygen uptake $\left(\dot{\mathrm{V}}_{2}\right)$ and carbon dioxide output $\left(\dot{\mathrm{V}}_{\mathrm{CO}_{2}}\right)$, as well as the HRV with spectral analysis (high- and low-frequency components of HRV, i.e., $\mathrm{CCV}_{\mathrm{HF}}$ and $\mathrm{CCV}_{\mathrm{LF}}$, reflecting cardiac parasympathetic and sympathetic activities, respectively), were measured in 66 healthy women aged 19-20 years after an overnight fast of $12 \mathrm{~h}$. Significant correlations were found between the $\mathrm{CCV}_{\mathrm{HF}}$ of $\mathrm{HRV}$ and both the end-tidal carbon dioxide concentration $\left(\mathrm{FETCO}_{2}\right)$ and gas exchange ratio $\left(\dot{\mathrm{V}}_{\mathrm{CO}_{2}} / \dot{\mathrm{V}}_{2}\right)$ in the subjects (partial correlation coefficients $r=0.354$ and 0.320 , respectively), whereas there was no significant connection between the $\mathrm{FETCO}_{2}$ and the $\dot{\mathrm{V}}_{\mathrm{CO}_{2}} / \dot{\mathrm{V}}_{2}$. Similarly, the $\mathrm{CCV}_{\mathrm{LF}}$ correlated significantly with the resting tidal volume of lung $(\mathrm{r}=0.364)$. These findings suggest that resting pulmonary ventilation function interacts with cardiac autonomic function assessed by the HRV, at least in healthy young adults, which may be useful for explaining the pathophysiology concerning the short-term effect of air pollution such as fine particulate matter on cardiovascular function.
\end{abstract}

An association between ambient air pollution and heart disease such as myocardial infarction or reduced heart rate variability (HRV), a marker of poor cardiac autonomic function, has been suggested by a number of epidemiological studies $(3-5,7,14-16$, $23,24,26,35)$. Especially, most of the cited literature reported that the reduced HRV has been connected with acute exposure to toxicants in air pollution such as fine particulate matter (especially, $<2.5 \mu \mathrm{m}$ in aerodynamic diameter, $\mathrm{PM}_{2.5}$ ), sulphur

Address correspondence to: Katsuyuki Murata, MD, Department of Environmental Health Sciences, Akita University School of Medicine, 1-1-1 Hondo, Akita 010-8543, Japan

Tel: +81-18-884-6085, Fax: +81-18-836-2608

E-mail: winestem@med.akita-u.ac.jp dioxide $\left(\mathrm{SO}_{2}\right)$, carbon monoxide, and ozone; whereas, Sullivan and coworkers (29) failed to find any significant relation of HRV parameters to increased residence levels of $\mathrm{PM}_{2.5}$ in elderly individuals. Hypothetical mechanisms for this association include 1) effects on the autonomic nervous system through direct reflexes from airways or through inflammatory response, 2) chemical effects on ion channel function in myocardial cells, 3) ischemic response in the myocardium, and 4) inflammatory responses that trigger endothelial dysfunction, atherosclerosis, and thrombosis (33). Nevertheless such air pollution should primarily affect pulmonary function, a link between the HRV parameters and pulmonary function does not always seem to be evident in healthy subjects or patients with cardiovascular disease.

Short-term variations in heart rate are seen at all 
ages and are an important sign of normal homeostatic mechanisms of the cardiovascular system (6). Especially, HRV with frequency-domain analysis has emerged as noninvasive method to assess cardiac autonomic activities quantitatively and is useful for the risk assessment of environmental neurotoxicants $(8,19)$. Apart from the HRV, spirometry has been employed as a standard technique of assessing lung function (2). However, parameters of the spirometry that needs vigorous respiratory efforts may not always have close relations to cardiac autonomic function, inasmuch as they generally exhibit dynamic pulmonary functions, e.g. due to aging or chronic pulmonary disease, but not acute pulmonary effects of environmental factors. In fact, though the adverse effect of air pollution on lung function such as forced expiratory volume in $1 \mathrm{sec}$ has been observed in some reports $(12,13,28,32)$, most of them were chronic features. Rather, resting pulmonary gas exchange function seems to be interactive because the route from respiratory movements to cardiovascular center through the intermediary of gas exchange and chemoreceptor reflex exists in the cardiovascular control mechanisms responsible for the main periodic fluctuations in heart rate $(9,34)$. For that reason, we used an expired gas analyzer, in addition to the HRV for healthy subjects, to examine an interaction between cardiac autonomic function and resting pulmonary ventilation function including oxygen uptake $\left(\dot{\mathrm{V}}_{2}\right)$ and carbon dioxide output $\left(\dot{\mathrm{V}}_{\mathrm{CO}}\right)$.

\section{MATERIALS AND METHODS}

The nature of the procedures used in this study was explained to college students in Akita, northern Japan, and the volunteers were invited to participate in our study. In total, 66 women aged 19-20 years (mean 19.7 years) were enrolled in this study (participation rate, $51 \%$ ). They were born in Akita Prefecture, where there are about $1,140,000$ populations. Also, the year-mean levels of suspended particulate matter $(\leq 10 \mu \mathrm{m}$ in aerodynamic diameter) at eleven spots of Akita City in 2005, reported by the Akita City Environment Sector, ranged from 14 to $24 \mu \mathrm{g} /$ $\mathrm{m}^{3}$, which were considerably lower than those in Tokyo $\left(25-42 \mu \mathrm{g} / \mathrm{m}^{3}\right)$; similarly, the year-mean levels at six spots of the same city were between 0.000 and $0.005 \mathrm{ppm}$ for $\mathrm{SO}_{2}$ and between 0.004 and $0.013 \mathrm{ppm}$ for nitrogen dioxide. Although some of the subjects had a part-time job such as waitress or cashier at the convenience store, they did not seem to have been exposed to air pollution occupational- ly. According to their self-report, there were no women either suffering from any obvious disease such as lung or cardiovascular disease or diabetes mellitus, or taking any medication. The study was carried out with their written informed consent and approval of the ethical review committee at the Akita University School of Medicine.

Pulmonary ventilation function and HRV were measured by a trained examiner, in the health care center of the college, with use of the Portable Expired Gas Analyzer AT-1100 (Anima Co., Tokyo) and the Pocket-ECG WEC-7101 (Nihon Kohden Co., Tokyo) connected to an analog-to-digital converter (sampling time, $1 \mathrm{msec}$ ) and a computer. The room temperature was kept between $18^{\circ} \mathrm{C}$ and $25^{\circ} \mathrm{C}$, and the environment was kept quiet. The height and body weight of each subject were measured to calculate body mass index (BMI) before conducting these physiological tests. These tests were conducted between $07: 30$ and $08: 30$ on weekdays after an overnight fast of $12 \mathrm{~h}$.

After each subject remained comfortably in the supine position for $5 \mathrm{~min}, 300 \mathrm{R}-\mathrm{R}$ intervals on electrocardiogram (ECG) were measured in real time and stored on a hard disc, and consecutive 100 $\mathrm{R}-\mathrm{R}$ intervals with the minimal standard deviation (S.D.) were automatically extracted from the obtained data to reduce measurement error $(8,11,18$, $21,25)$. The $\mathrm{CV}_{\mathrm{RR}}(\%)$ was defined as the ratio of the S.D. of the R-R intervals to the average value $\left(\mathrm{RR}_{\text {mean }}, \mathrm{msec}\right)$. The power spectrum of R-R intervals was computed by autoregressive spectral analysis according to the Akaike information criteria (1). The spectrum of each of two components, i.e., the high frequency (HF) component at the center frequency of $0.15-0.4 \mathrm{~Hz}$ and low frequency (LF) component at $0.01-0.15 \mathrm{~Hz}$, was separated by component analysis. Each component coefficient of variation (i.e., $\mathrm{CCV}_{\mathrm{HF}}$ and $\mathrm{CCV}_{\mathrm{LF}}$ ) was defined as the ratio of the square root of each component power spectral density $\left(\mathrm{PSD}_{\mathrm{k}}, \mathrm{msec}^{2}\right)$ to the $\mathrm{RR}_{\text {mean }}: \mathrm{CCV}_{\mathrm{k}}$ $(\%)=100 \times\left(\mathrm{PSD}_{\mathrm{k}}\right)^{1 / 2} / \mathrm{RR}_{\text {mean }}$, where $\mathrm{k}=\mathrm{HF}$ or $\mathrm{LF}$. Since parasympathetic blockade with atropine abolishes the HF component but $\beta$-sympathetic blockade has no effect, the $\mathrm{PSD}_{\mathrm{HF}}$ and $\mathrm{CCV}_{\mathrm{HF}}$ reflect the parasympathetic activity $(22,31)$. In addition, the LF component is considered to be derived from the fluctuation in the vasomotor activity through the baroreflex mechanism and to show a $\beta$-adrenergically mediated increase in the standing posture. Therefore, the $\mathrm{PSD}_{\mathrm{LF}}$ and $\mathrm{CCV}_{\mathrm{LF}}$ are thought to reflect mainly the sympathetic activities, and the LF/HF ratio (i.e., $\mathrm{PSD}_{\mathrm{LF}} / \mathrm{PSD}_{\mathrm{HF}}$ ) represents a sympathovagal 
balance.

Pulmonary ventilation function was examined according to the measurement procedure of basal metabolic rate. At first, the mask, designed to fit comfortably without any air leakage, was fixed on the subject's mouth. After resting for at least $10 \mathrm{~min}$ in the sitting position, this test was conducted using the above expired gas analyzer that employed a newly developed ultrasound flow meter, together with galvanic cell type oxygen sensor and infrared carbon dioxide sensor, covering a wide range of flow rate and enabled measurements of $\dot{\mathrm{V}}_{2}$ and $\dot{\mathrm{V}}_{\mathrm{CO}_{2}}$ in breath. The expired gas analyzer was calibrated with gas mixtures of known $\mathrm{O}_{2}$ and $\mathrm{CO}_{2}$ concentrations before testing. Analog output channels were continuously displayed on screen, and digitally acquired onto a notebook computer at $100 \mathrm{~Hz}$ sampling frequency. The detailed validity and compatibility of the device have been presented in another report (30). Average values of pulmonary ventilation parameters calculated from 8-min data for each subject, during subsequent off-line analysis, were as follows: respiratory frequency (RF, cycles/min), breath-by-breath tidal volume $(\mathrm{VT}, \mathrm{L}), \dot{\mathrm{V}}_{2}(\mathrm{~mL} /$ $\mathrm{min}), \dot{\mathrm{V}} \mathrm{CO}_{2}(\mathrm{~mL} / \mathrm{min})$, gas exchange ratio $\left(\dot{\mathrm{V}}_{\mathrm{CO}_{2}} /\right.$ $\left.\dot{\mathrm{V}}_{2}\right)$, expired oxygen concentration $\left(\mathrm{FEO}_{2}, \%\right)$, expired carbon dioxide concentration $\left(\mathrm{FECO}_{2}, \%\right)$, endtidal oxygen concentration $\left(\mathrm{FETO}_{2}, \%\right)$, and end-tidal carbon dioxide concentration $\left(\mathrm{FETCO}_{2}, \%\right)$.

Since the $\mathrm{PSD}_{\mathrm{LF}}$ and $\mathrm{PSD}_{\mathrm{HF}}$ of the HRV were highly skewed to the left, these were transformed into common logarithmic values in the following analysis. To examine the relationships between the HRV and pulmonary ventilation parameters, the simple and partial correlation coefficients (r) were calculated, using the age, BMI and smoking habit as possible confounders. Smoking habit was scored as "non-smoker" $=0$ and "smoker" $=1$. All analyses with two-sided P values were performed with the Statistical Package for the Biosciences (20).

\section{RESULTS}

There were no subjects with either abnormal beats or ventricular extrasystoles on ECG, and no subject took medication or caffeine-containing products on the morning of the examination. Table 1 presents the basal characteristics, pulmonary ventilation parameters, and HRV parameters in 66 women. Although eighteen of them had drinking habit, it was not significantly related to either pulmonary ventilation or HRV parameters $(\mathrm{P}>0.05$, data not shown). Correlation matrices among pulmonary ventilation param- eters and among HRV parameters in the 66 women are shown in Tables 2 and 3, respectively.

In using the Pearson product-moment correlation coefficient, the $\mathrm{CCV}_{\mathrm{LF}}$ and log-transformed $\mathrm{PSD}_{\mathrm{LF}}$ were positively correlated with the $\mathrm{VT}, \mathrm{FETCO}_{2}$, and $\dot{\mathrm{V}}_{\mathrm{CO}_{2}} / \dot{\mathrm{V}}_{2}$ among the 66 women (Table 4). Similarly, the $\mathrm{CCV}_{\mathrm{HF}}$ and log-transformed $\mathrm{PSD}_{\mathrm{HF}}$ were positively correlated with the $\mathrm{FETCO}_{2}$ and $\dot{\mathrm{V}}_{\mathrm{CO}_{2}} / \dot{\mathrm{V}}_{2}$. These results were almost similar to those when using the partial correlation coefficients after adjusting for age, BMI, and smoking habit (Table 4). Given the multiple significance test (17), the correlations between the $\mathrm{VT}_{\mathrm{T}}$ and the $\mathrm{CCV}_{\mathrm{LF}}$, between the $\mathrm{FETCO}_{2}$ and both the $\mathrm{CV}_{\mathrm{RR}}$ and $\mathrm{CCV}_{\mathrm{HF}}$, and between the $\dot{\mathrm{V}}_{\mathrm{CO}_{2}} / \dot{\mathrm{V}}_{2}$ and both the $\mathrm{CV}_{\mathrm{RR}}$ and log-transformed $\mathrm{PSD}_{\mathrm{HF}}$ remained statistically significant $(\mathrm{P}<0.05)$. Figure 1 illustrates significant relationships between the $\dot{\mathrm{V}}_{\mathrm{CO}_{2}} / \dot{\mathrm{V}}_{2}$ and $\mathrm{HRV}$ parameters (i.e., $\mathrm{CV}_{\mathrm{RR}}$ and $\mathrm{CCV}_{\mathrm{HF}}$ ).

\section{DISCUSSION}

The $\mathrm{CV}_{\mathrm{RR}}$, a comprehensive marker of cardiac autonomic function, seems to reflect the parasympathetic activity rather than the sympathetic one as shown in Table 3, though the two parameters (i.e., $\mathrm{CCV}_{\mathrm{HF}}$ and $\mathrm{CCV}_{\mathrm{LF}}$ ) in principle contribute to the $\mathrm{CV}_{\mathrm{RR}}(18)$. In this sense, the parasympathetic activity of the HRV had positively close relation to the $\mathrm{FETCO}_{2}$ under physiological conditions in healthy women occupationally unexposed to air pollution (Table 4). This finding is physiologically reasonable and can be explained as follows: The increased end-tidal $\mathrm{CO}_{2}$ concentration is transmitted to the arterial and central chemoreceptors and the respiratory modulation of the cardiac autonomic nervous system is activated through the chemoreceptor reflex (9). On the contrary, the reduced end-tidal $\mathrm{CO}_{2}$ concentration due to a certain environmental factor may lower the $\mathrm{CV}_{\mathrm{RR}}$ and $\mathrm{CCV}_{\mathrm{HF}}$.

The sympathetic activity of the HRV (i.e., $\mathrm{CCV}_{\mathrm{LF}}$ ) showed a positive correlation with resting tidal volume in this study. Normally, tidal volume becomes considerably larger during heavy exercise than at rest (9), presumably implying that the cardiac sympathetic drive is activated during the exercise. Our finding suggested that such an interaction between tidal volume and cardiac sympathetic activity could exist even at rest. During normal levels of tidal breathing, on the other hand, most of the respiratory phase influence on muscle sympathetic outflow in normal conscious subjects has been considered to be independent of baroreceptor-sensed fluctuations in 
Table 1 Basal characteristics, pulmonary ventilation and heart rate variability (HRV) parameters in 66 Japanese women (mean \pm S.D.)

\begin{tabular}{|c|c|c|c|}
\hline & \multicolumn{2}{|c|}{ Mean \pm S.D. } & 5 and 95 percentiles \\
\hline \multicolumn{4}{|l|}{ Basal characteristics: } \\
\hline Height $(\mathrm{cm})$ & $159.8 \pm$ & 5.8 & $150.4-167.3$ \\
\hline Body weight (kg) & $54.6 \pm$ & 10.0 & $42.6-70.5$ \\
\hline Body mass index $\left(\mathrm{kg} / \mathrm{m}^{2}\right)$ & $21.4 \pm$ & 3.6 & $17.4-27.1$ \\
\hline Ear temperature $\left({ }^{\circ} \mathrm{C}\right)$ & $36.6 \pm$ & 0.5 & $35.8-37.7$ \\
\hline Smoker (number) & $7(11 \%$ & & \\
\hline \multicolumn{4}{|l|}{ Pulmonary ventilation parameters: } \\
\hline Respiratory frequency (RF, cycles/min) & $15 \pm$ & 4 & $9-20$ \\
\hline Tidal volume $(\mathrm{VT}, \mathrm{L})$ & $0.4 \pm$ & 0.1 & $0.3-0.6$ \\
\hline Oxygen uptake $\left(\dot{\mathrm{V}}_{2}, \mathrm{~mL} / \mathrm{min}\right)$ & $171.5 \pm$ & 26.8 & $133.1-221.7$ \\
\hline Carbon dioxide output $\left(\dot{\mathrm{V}}_{\mathrm{CO}_{2}}, \mathrm{~mL} / \mathrm{min}\right)$ & $130.8 \pm$ & 18.2 & $106.8-165.0$ \\
\hline Gas exchange ratio $\left(\dot{\mathrm{V}}_{\mathrm{CO}_{2}} / \dot{\mathrm{VO}}_{2}\right)$ & $0.77 \pm$ & 0.08 & $0.69-\quad 0.92$ \\
\hline Expired oxygen level $\left(\mathrm{FEO}_{2}, \%\right)$ & $17.8 \pm$ & 0.4 & $16.5-17.7$ \\
\hline Expired carbon dioxide level $\left(\mathrm{FECO}_{2}, \%\right)$ & $3.1 \pm$ & 0.3 & $2.8-3.6$ \\
\hline End-tidal oxygen level $\left(\mathrm{FETO}_{2}, \%\right)$ & $15.3 \pm$ & 0.6 & $14.3-16.3$ \\
\hline End-tidal carbon dioxide level $\left(\mathrm{FETCO}_{2}, \%\right)$ & $5.1 \pm$ & 0.4 & $4.5-5.7$ \\
\hline \multicolumn{4}{|l|}{ HRV parameters: } \\
\hline Heart rate (beats/min) & $69 \pm$ & 10 & $55-87$ \\
\hline $\mathrm{CV}_{\mathrm{RR}}(\%)$ & $4.60 \pm$ & 2.00 & $2.21-$ \\
\hline $\mathrm{CCV}_{\mathrm{LF}}(\%)$ & $2.69 \pm$ & 1.27 & $1.06-$ \\
\hline $\operatorname{PSD}_{\mathrm{LF}}\left(\mathrm{msec}^{2}\right)$ & $705.5 \pm$ & 732.7 & $86.5-1874$ \\
\hline $\mathrm{CCV}_{\mathrm{HF}}(\%)$ & $3.29 \pm$ & 1.74 & $1.18-\quad 6.70$ \\
\hline $\operatorname{PSD}_{\mathrm{HF}}\left(\mathrm{msec}^{2}\right)$ & $1196 \pm 1$ & 516 & $97.9-3938$ \\
\hline $\mathrm{LF} / \mathrm{HF}$ ratio & $1.35 \pm$ & 2.12 & $0.15-\quad 6.95$ \\
\hline
\end{tabular}

Abbreviations are represented in the Materials AND Methods.

Table 2 Correlation matrix among resting pulmonary ventilation parameters in 66 Japanese women: results of Pearson product-moment correlation coefficients

\begin{tabular}{|c|c|c|c|c|c|c|c|c|}
\hline Parameters & $\mathrm{RF}$ & VT & $\dot{\mathrm{V}}_{\mathrm{O}_{2}}$ & $\dot{\mathrm{V}} \mathrm{CO}_{2}$ & $\dot{\mathrm{V}} \mathrm{CO}_{2} / \dot{\mathrm{V}}_{\mathrm{O}_{2}}$ & $\mathrm{FEO}_{2}$ & $\mathrm{FECO}_{2}$ & $\mathrm{FETO}_{2}$ \\
\hline $\mathrm{VT}_{\mathrm{T}}$ & $-0.591 * *$ & & & & & & & \\
\hline$\dot{\mathrm{V}}_{2}$ & $0.346^{* *}$ & 0.004 & & & & & & \\
\hline$\dot{\mathrm{V}} \mathrm{CO}_{2}$ & $0.299 *$ & 0.021 & $0.815^{* *}$ & & & & & \\
\hline$\dot{\mathrm{V}} \mathrm{CO}_{2} / \dot{\mathrm{V}}_{2}$ & -0.168 & 0.147 & $-0.469 * *$ & 0.114 & & & & \\
\hline $\mathrm{FEO}_{2}$ & 0.041 & 0.140 & $-0.498 * *$ & -0.218 & $-0.557 * *$ & & & \\
\hline $\mathrm{FECO}_{2}$ & -0.159 & -0.141 & 0.181 & $0.383 * *$ & 0.215 & $-0.675^{* *}$ & & \\
\hline $\mathrm{FETO}_{2}$ & $0.317 * *$ & -0.239 & $-0.257^{*}$ & 0.030 & $0.477 * *$ & $0.834 * *$ & $-0.515^{* *}$ & \\
\hline $\mathrm{FETCO}_{2}$ & $-0.348 * *$ & 0.188 & 0.073 & 0.094 & 0.000 & $-0.637 * *$ & $0.732 * *$ & $-0.810 * *$ \\
\hline
\end{tabular}

$* \mathrm{P}<0.05 ; * * \mathrm{P}<0.01$.

Abbreviations are represented in the MATERIALS AND METHODS and Table 1.

intrathoracic or intravascular pressures and of lung inflation-stimulated vagal afferent activity (27). Further study is needed to better understand the role of cardiac sympathetic function in the cardiorespiratory network at rest.

The resting $\dot{\mathrm{V}} \mathrm{CO}_{2} / \dot{\mathrm{V}}_{2}$ was significantly related to the $\mathrm{CV}_{\mathrm{RR}}$ and log-transformed $\mathrm{PSD}_{\mathrm{HF}}$ in the healthy women (Table 4 and Fig. 1). The gas exchange ratio $\left(\dot{\mathrm{V}}_{\mathrm{CO}_{2}} / \dot{\mathrm{V}}_{2}\right)$ is known as the respiratory quotient (RQ). The mean $\dot{\mathrm{V}}_{\mathrm{CO}_{2}} / \dot{\mathrm{V}}_{2}$ in our subjects was 0.77 (Table 1), although well-nourished subjects on a typical Western diet had a resting RQ of approximately 0.85 , reflecting the mixture of fats and carbohydrates being metabolized (9). This difference thus may have 
Table 3 Correlation matrix among heart rate variability parameters in 66 Japanese women: results of Pearson product-moment correlation coefficients

\begin{tabular}{|c|c|c|c|c|c|c|}
\hline Parameters & Heart rate & $\mathrm{CV}_{\mathrm{RR}}$ & $\mathrm{CCV}_{\mathrm{LF}}$ & $\log \left[\mathrm{PSD}_{\mathrm{LF}}\right]^{\mathrm{a}}$ & $\mathrm{CCV}_{\mathrm{HF}}$ & $\log \left[\mathrm{PSD}_{\mathrm{HF}}\right]^{\mathrm{a}}$ \\
\hline $\mathrm{CV}_{\mathrm{RR}}$ & $-0.391 * *$ & & & & & \\
\hline $\mathrm{CCV}_{\mathrm{LF}}$ & 0.016 & $0.638^{* *}$ & & & & \\
\hline $\log \left[\mathrm{PSD}_{\mathrm{LF}}\right]^{\mathrm{a}}$ & $-0.256^{*}$ & $0.721 * *$ & $0.914 * *$ & & & \\
\hline $\mathrm{CCV}_{\mathrm{HF}}$ & $-0.334 * *$ & $0.903 * *$ & $0.405 * *$ & $0.513 * *$ & & \\
\hline $\log \left[\mathrm{PSD}_{\mathrm{HF}}\right]^{\mathrm{a}}$ & $-0.571 * *$ & $0.834 * *$ & $0.371 * *$ & $0.541 * *$ & $0.909 * *$ & \\
\hline LF/HF ratio & $0.278 *$ & -0.172 & 0.242 & 0.173 & $-0.422 * *$ & $-0.577 * *$ \\
\hline
\end{tabular}

$* \mathrm{P}<0.05 ; * * \mathrm{P}<0.01$

Abbreviations are represented in the MATERIALS AND METHODS and Table 1.

${ }^{a} \log$-transformed $\mathrm{PSD}_{\mathrm{LF}}$ or $\mathrm{PSD}_{\mathrm{HF}}$.

Table 4 Relationships between resting pulmonary ventilation parameters and heart rate variability parameters in 66 Japanese women: results of correlation analyses

\begin{tabular}{|c|c|c|c|c|c|c|c|}
\hline & Heart rate & $\mathrm{CV}_{\mathrm{RR}}$ & $\mathrm{CCV}_{\mathrm{LF}}$ & $\log \left[\mathrm{PSD}_{\mathrm{LF}}\right]^{\mathrm{a}}$ & $\mathrm{CCV}_{\mathrm{HF}}$ & $\log \left[\mathrm{PSD}_{\mathrm{HF}}\right]^{\mathrm{a}}$ & $\mathrm{LF} / \mathrm{HF}$ \\
\hline \multicolumn{8}{|c|}{ Pearson product-moment correlation coefficients: } \\
\hline $\mathrm{RF}$ & -0.030 & -0.029 & -0.175 & -0.140 & 0.015 & 0.006 & -0.132 \\
\hline VT & 0.056 & 0.187 & $0.372 * *$ & $0.299 *$ & 0.060 & 0.063 & 0.198 \\
\hline$\dot{\mathrm{V}}_{2}$ & 0.194 & -0.116 & -0.148 & $-0.252 *$ & -0.074 & -0.170 & 0.070 \\
\hline$\dot{\mathrm{V}} \mathrm{CO}_{2}$ & 0.046 & 0.119 & -0.024 & -0.113 & 0.143 & 0.058 & -0.022 \\
\hline$\dot{\mathrm{V}} \mathrm{CO}_{2} / \dot{\mathrm{V}}_{2}$ & -0.222 & $0.379 * *$ & $0.261 *$ & $0.282 *$ & $0.343 * *$ & $0.381 * *$ & -0.164 \\
\hline $\mathrm{FEO}_{2}$ & -0.230 & 0.163 & 0.098 & 0.147 & 0.110 & 0.237 & -0.134 \\
\hline $\mathrm{FECO}_{2}$ & 0.008 & 0.149 & 0.078 & 0.060 & 0.183 & 0.077 & -0.004 \\
\hline $\mathrm{FETO}_{2}$ & -0.113 & -0.015 & -0.101 & -0.070 & 0.003 & 0.088 & -0.135 \\
\hline $\mathrm{FETCO}_{2}$ & -0.065 & $0.312 *$ & $0.251^{*}$ & $0.247 *$ & $0.292 *$ & 0.184 & 0.030 \\
\hline \multicolumn{8}{|c|}{ Partial correlation coefficients: ${ }^{b}$} \\
\hline $\mathrm{RF}$ & -0.083 & 0.027 & -0.163 & -0.121 & 0.070 & 0.059 & -0.153 \\
\hline $\mathrm{VT}_{\mathrm{T}}$ & 0.086 & 0.161 & $0.364 * *$ & $0.281 *$ & 0.022 & 0.023 & 0.202 \\
\hline$\dot{\mathrm{V}}_{2}$ & 0.172 & -0.086 & -0.130 & -0.232 & -0.040 & -0.133 & 0.062 \\
\hline$\dot{\mathrm{V}} \mathrm{CO}_{2}$ & 0.054 & 0.126 & -0.021 & -0.106 & 0.161 & 0.074 & -0.010 \\
\hline$\dot{\mathrm{V}} \mathrm{CO}_{2} / \dot{\mathrm{VO}}_{2}$ & -0.179 & $0.351 * *$ & 0.245 & $0.270 *$ & $0.320 *$ & $0.354 * *$ & -0.139 \\
\hline $\mathrm{FEO}_{2}$ & -0.204 & 0.118 & 0.046 & 0.096 & 0.044 & 0.149 & -0.119 \\
\hline $\mathrm{FECO}_{2}$ & -0.001 & 0.209 & 0.138 & 0.129 & $0.275^{*}$ & 0.186 & -0.005 \\
\hline $\mathrm{FETO}_{2}$ & -0.100 & -0.043 & -0.146 & -0.113 & -0.030 & 0.031 & -0.126 \\
\hline $\mathrm{FETCO}_{2}$ & -0.063 & $0.359 * *$ & $0.310^{*}$ & $0.312 *$ & $0.354 * *$ & $0.261^{*}$ & 0.038 \\
\hline
\end{tabular}

$* \mathrm{P}<0.05 ; * * \mathrm{P}<0.01$.

Abbreviations are represented in the MATERIALS AND METHODS and Table 1.

${ }^{a} \log$-transformed $\mathrm{PSD}_{\mathrm{LF}}$ or $\mathrm{PSD}_{\mathrm{HF}}$

${ }^{\mathrm{b}}$ Age, body mass index, and smoking habit were used as possible confounders.

depended on consumed food. Also, the $\dot{\mathrm{V}} \mathrm{CO}_{2} / \dot{\mathrm{V}}_{2}$, measured at the lungs (i.e., pulmonary gas exchange ratio, PRQ), does not correspond with the above RQ exactly (9): At first, PRQ becomes less than RQ when subjects hypoventilate and retain $\mathrm{CO}_{2}$ in the body stores; secondly, when subjects hyperventilate and wash $\mathrm{CO}_{2}$ out of the body stores, PRQ exceeds RQ; thirdly, PRQ exceeds RQ consequent to the additional $\mathrm{CO}_{2}$ when tissue bicarbonate concentration is decreasing during an acute metabolic acidosis.
That is, the $\dot{\mathrm{V}}_{\mathrm{CO}_{2}} / \dot{\mathrm{V}}_{2}$ appears to express alveolar ventilation function as well as resting metabolic rate. On the other hand, since no significant correlation was seen between the $\mathrm{FETCO} 2$ and $\dot{\mathrm{V}}_{\mathrm{CO}_{2}} / \dot{\mathrm{V}}_{2}$ (Table 2), it would be difficult to think that the $\dot{\mathrm{V}}_{\mathrm{CO}_{2}} / \dot{\mathrm{V}}_{2}$ reflects alveolar ventilation function. Consequently, the association between the $\dot{\mathrm{V}} \mathrm{CO}_{2} / \dot{\mathrm{V}}_{2}$ and cardiac parasympathetic activity may suggest the impact of dietary balance on cardiac parasympathetic function, i.e., a potential confounder, in healthy 


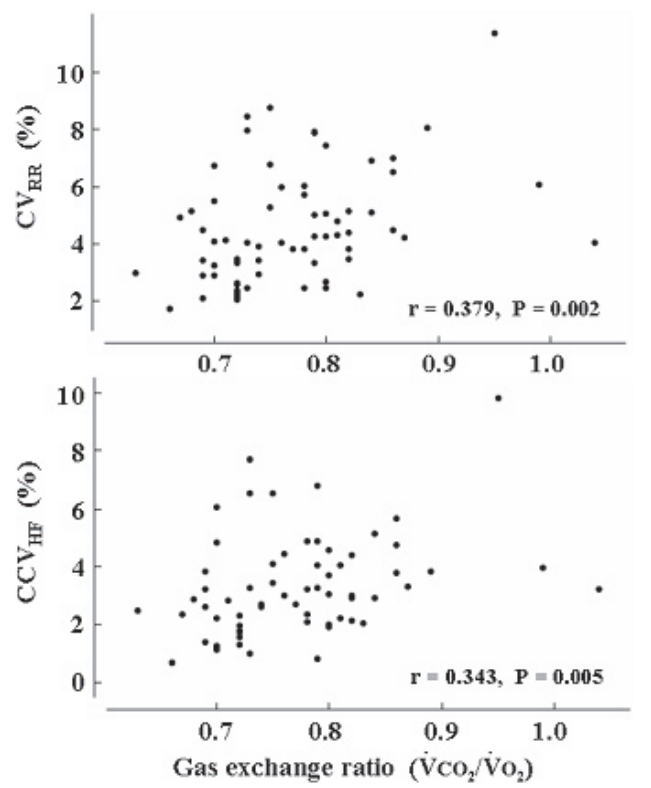

Fig. 1 Relationships between resting gas exchange ratio $\left(\mathrm{V}_{\mathrm{CO}_{2}} / \dot{\mathrm{V}}_{2}\right)$ and two heart rate variability parameters $\left(\mathrm{CV}_{\mathrm{RR}}\right.$ and $\mathrm{CCV}_{\mathrm{HF}}$, reflecting cardiac autonomic and parasympathetic activities, respectively) in 66 Japanese women. $r$ and $\mathrm{P}$ represent a Pearson product-moment correlation coefficient and probability.

subject. This implication awaits further nutritional research with the HRV.

In the present study, no significant association between respiratory frequency and any HRV parameters was found in stationary conditions among the healthy women (Table 3), although Hirsch and Bishop (10) reported that the $\mathrm{PSD}_{\mathrm{HF}}$ decreased with increasing breathing frequency when it exceeded 6 cycles per minute. This disagreement would be attributable to the different study design, that is, observational data at rest in a population and timedomain experimental data in some subjects. In the latter, each subject was instructed to change the breathing frequency by the authors successively. Resting respiratory frequency of $9-20$ cycles/min in healthy population does not seem to affect cardiac autonomic function so strongly.

There may have been some possible limitations in our study. Our subjects were all female and the age range was very small (i.e., 19 and 20 years old); for this reason, it may not be easy to generalize our results to a general population including males or the aged. Also, we had no data of dynamic pulmonary functions because a spirometer was not employed. Nonetheless, the validity of the HRV and expired gas analyzer used in this study was confirmed previously $(11,18,21,30)$ and these data seemed to pre- serve internal consistency (Tables 2 and 3); whereas, the mean $\dot{\mathrm{V}}_{2}, \dot{\mathrm{V}}_{\mathrm{CO}_{2}}$, and $\mathrm{VT}$ in our subjects (Table 1) were somewhat lower than typical values of respiratory and gas transport quantities at rest (9), which would have been due to difference of attributes such as age and sex between two study populations. Of course, the environment of these tests was kept constant. In addition, smoking habit and BMI, affecting lung function, were used as confounders in the process of data analysis. Thus, it is suggested that our findings were not heavily influenced by measurement error or confounding bias.

In conclusion, evidence was provided regarding the interaction between cardiac parasympathetic function and pulmonary ventilation function involved in the end-tidal $\mathrm{CO}_{2}$ concentration under physiological conditions in humans. Nowadays, special attention is directed to the pathophysiology of heart disease and reduced HRV resulting from ambient air pollution (36). In this sense, our finding on the cardiorespiratory network may be useful for explaining the pathophysiology concerning the influence of air pollution such as $\mathrm{PM}_{2.5}$ on cardiovascular function. Further study with an expired gas analyzer is necessary to investigate a link between lung and heart functions in many elderly subjects or subjects exposed to $\mathrm{PM}_{2.5}$.

\section{Acknowledgments}

This study was supported partly by a grant-in-aid for scientific research from the Ministry of Education, Culture, Sports, Science and Technology, Japan.

\section{REFERENCES}

1. Akaike H (1974) A new look at the statistical model identification. IEEE Trans Automat Contr 19, 716-723.

2. American Thoracic Society (1987) Standardization of spirometry-1987 update. Statement of the American Thoracic Society. Am Rev Respir Dis 136, 1285-1298.

3. Chan C-C, Chuang K-J, Shiao G-M and Lin L-Y (2004) Personal exposure to submicrometer particles and heart rate variability in human subjects. Environ Health Perspect 112, 1063-1067.

4. Chen J-C, Stone PH, Verrier RL, Nearing BD, MacCallum G, Kim J-Y, Herrick RF, You J, Zhou H and Christiani DC (2006) Personal coronary risk profiles modify autonomic nervous system responses to air pollution. J Occup Environ Med 48, 1133-1142.

5. Dockery DW (2001) Epidemiologic evidence of cardiovascular effects of particulate air pollution. Environ Health Perspect 109, 483-486.

6. Finley JP and Nugent ST (1995) Heart rate variability in infants, children and young adults. J Auton Nerv Syst 51, 103 108. 
7. Gold DR, Litonjua A, Schwartz J, Lovett E, Larson A, Nearing B, Allen G, Verrier M, Cherry R and Verrier R (2000) Ambient pollution and heart rate variability. Circulation 101, $1267-1273$.

8. Grandjean P, Murata K, Budtz-Jørgensen E and Weihe P (2004) Cardiac autonomic activity in methylmercury neurotoxicity: 14-year follow-up of a Faroese birth cohort. $J$ Pediatr 144, 169-176.

9. Greger R and Windhorst U (1996) Comprehensive Human Physiology, Vol. 2. pp2015-2144, Springer-Verlag, Berlin.

10. Hirsch JA and Bishop B (1981) Respiratory sinus arrhythmia in humans: how breathing pattern modulates heart rate. $\mathrm{Am} \mathrm{J}$ Physiol 241, H620-H629.

11. Ishii N, Dakeishi M, Sasaki M, Iwata T and Murata K (2005) Cardiac autonomic imbalance in female nurses with shift work. Auton Neurosci 122, 94-99.

12. Karita K, Yano E, Jinsart W, Boudoung D and Tamura K (2001) Respiratory symptoms and pulmonary function among traffic police in Bangkok, Thailand. Arch Environ Health 56, 467-470.

13. Langkulsen U, Jinsart W, Karita K and Yano E (2006) Respiratory symptoms and lung function in Bangkok school children. Eur J Public Health 16, 676-681.

14. Liao D, Creason J, Shy C, Williams R, Watts R and Zweidinger R (1999) Daily variation of particulate air pollution and poor cardiac autonomic control in the elderly. Environ Health Perspect 107, 521-525.

15. Liao D, Duan Y, Whitsel EA, Zheng Z, Heiss G, Chinchilli VM and Lin H-M (2004) Association of higher levels of ambient criteria pollutants with impaired cardiac autonomic control: a population-based study. Am J Epidemiol 159, 768777.

16. Magari SR, Hauser R, Schwartz J, Williams PL, Smith TJ and Christiani DC (2001) Association of heart rate variability with occupational and environmental exposure to particulate air pollution. Circulation 104, 986-991.

17. Morrison DF (1976) Multivariate Statistical Methods, 2nd edn. pp116-120, McGraw-Hill, New York.

18. Murata K, Landrigan PJ and Araki S (1992) Effects of age heart rate, gender, tobacco and alcohol ingestion on R-R interval variability in human ECG. J Auton Nerv Syst 37, 199206.

19. Murata K and Araki S (1996) Assessment of autonomic neurotoxicity in occupational and environmental health as determined by ECG R-R interval variability: a review. Am $J$ Ind Med 30, 155-163.

20. Murata K and Yano E (2002) Medical Statistics for Evidence-Based Medicine with SPBS User's Guide. Nankodo Publisher, Tokyo. (In Japanese)

21. Murata K, Yano E, Hashimoto H, Karita K and Dakeishi M (2005) Effects of shift work on QTc interval and blood pressure in relation to heart rate variability. Int Arch Occup Environ Health 78, 287-292.

22. Pagani M, Lombardi F, Guzzetti S, Rimoldi O, Furlan R, Pizzinelli P, Sandrone G, Malfatto G, Dell'Orto S, Piccaluga E, Turiel M, Baselli G, Cenitti S and Malliani A (1986) Power spectral analysis of heart rate and arterial pressure variabilities as a marker of sympatho-vagal interaction in man and conscious dog. Circ Res 59, 178-193.
23. Pope CA III, Hansen ML, Long RW, Nielsen KR, Eatough NL, Wilson WE and Eatough DJ (2003) Ambient particulate air pollution, heart rate variability, and blood markers of inflammation in a panel of elderly subjects. Environ Health Perspect 112, 339-345.

24. Samet JM, Dominici F, Curriero FC, Coursac I and Zeger SL (2000) Fine particulate air pollution and mortality in 20 U.S. cities, 1987-1994. N Engl J Med 343, 1742-1749.

25. Sampei M, Dakeishi M, Wood DC, Iwata T and Murata K (2007) Spontaneous awakening from nocturnal sleep and cardiac autonomic function in preschool children. Auton Neurosci 133, 170-174.

26. Schwartz J, Litonjua A, Suh H, Verrier M, Zanobetti A, Syring $M$, Nearing B, Verrier R, Stone P, MacCallum G, Speizer FE and Gold DR (2005) Traffic related pollution and heart rate variability in a panel of elderly subjects. Thorax $\mathbf{6 0}$, 455-461.

27. Seals DR, Suwarno NO, Joyner MJ, Iber C, Copeland JG and Dempsey JA (1993) Respiratory modulation of muscle sympathetic nerve activity in intact and lung denervated humans. Circ Res 72, 440-454

28. Sekine K, Shima M, Nitta Y and Adachi M (2004) Long term effects of exposure to automobile exhaust on the pulmonary function of female adults in Tokyo, Japan. Occup Environ Med 61, 350-357.

29. Sullivan JH, Schreuder AB, Trenga CA, Liu SL-J, Larson TV, Koenig JQ and Kaufman JD (2005) Association between short term exposure to fine particulate matter and heart rate variability in older subjects with and without heart disease. Thorax 60, 462-466.

30. Tajima A and Itoh H (2006) The validity of portable expired gas analyzer and its compatibility with a reference analyzer. Respir Circ 54, 657-662. (In Japanese)

31. Task Force of the European Society of Cardiology and the North American Society of Pacing and Electrophysiology (1996) Heart rate variability: standards of measurement, physiological interpretation, and clinical use. Circulation 93, 1043-1065.

32. Trenga CA, Sullivan JH, Schildcrout JS, Shepherd KP, Shapiro GG, Liu L-JS, Kaufman JD and Koenig JQ (2006) Effect of particulate air pollution on lung function in adult and pediatric subjects in a Seattle panel study. Chest 129, 16141622.

33. Utell MJ, Frampton MW, Zareba W, Devlin RB and Cascio WE (2002) Cardiovascular effects associated with air pollution: potential mechanisms and methods of testing. Inhal Toxicol 14, 1231-1247.

34. van Ravenswaaij-Arts CMA, Kollee LAA, Hopman JCW, Stoelinga GBA and van Geijn HP (1993) Heart rate variability. Ann Intern Med 118, 436-447.

35. Wheeler A, Zanobetti A, Gold DR, Schwartz J, Stone P and Suh HH (2006) The relationship between ambient air pollution and heart rate variability differs for individuals with heart and pulmonary disease. Environ Health Perspect 114, 560-566.

36. Zareba W, Nomura A and Couderc JP (2001) Cardiovascular effects of air pollution: what to measure in ECG? Environ Health Perspect 109 (suppl 4), 533-538. 
